\title{
Electrodeposition of Thin Film Cu-Zn Shape Memory Alloys
}

D. Page and S. Roy

Department of Chemical and Process Engineering, University of Newcastle-upon-Tyne, Merz Court NEI 7RU, U.K.

\begin{abstract}
Cu}-\mathrm{Zn}$ alloys have been electrodeposited from a pyrophosphate electrolyte containing $\mathrm{Cu}_{2} \mathrm{P}_{2} \mathrm{O}_{7}, \mathrm{Zn}_{2} \mathrm{P}_{2} \mathrm{O}_{7}$ salts and an excess of $\mathrm{K}_{4} \mathrm{P}_{2} \mathrm{O}_{7}$ and $\mathrm{KNO}_{3}$. Current-potential data for both copper and zinc, as well their plating current efficiencies were determined from electrochemical polarisation experiments. Copper deposition commenced at potentials below $-0.208 \mathrm{~V}$ whereas zinc was deposited only below $-1.157 \mathrm{~V}$. The current efficiencies for both metals were found to be low; typically $20-50 \%$ for copper and $5-10 \%$ for zinc. Although the potentials for electroreduction for the two components are disparate, alloys of brass containing $30-50 \% \mathrm{Cu}$ were successfully produced with a current efficiency of $20 \%$. Brass foils as thin as $10 \mu \mathrm{m}$ were produced by this method. The deposits were found to consist predominantly of $\alpha$ and $\beta$ phases. It was found brass deposition on a copper substrate was preceded by a $1.5 \mu \mathrm{m}$ thick $\mathrm{CuZn}_{\mathbf{s}}$ layer.
\end{abstract}

\section{INTRODUCTION}

Currently, shape memory alloys are manufactured by metallurgical means into wires, rods, foils, etc. by melting, casting and shaping followed by heat treatment cycles to obtain desired shape memory properties. Metallurgical methods, however, cannot be easily used to fabricate shape memory thin films which has great potential in the field of micro-technology. A few investigations have been carried out to fabricate thin films of shape memory materials by physical vapour deposition methods. Although the experimental findings are yet inconclusive, some studies have indicated that thin films of shape memory materials could have a high power to volume ratio than that observed in bulk shape memory alloys [1].

A second method, which can be used to fabricate these materials, is electrodeposition, which is currently used to manufacture magnetic, wear and corrosion resistant thin films. There has been a prior attempt to fabricate shape memory thin film by electrodeposition by J.Frimpong et al [2]. They produced a $\mathrm{Cu}-\mathrm{Zn}$ alloy which displayed shape memory effects during simple bending tests. However, the shape memory experiments were not entirely systematic which led to several contradictions and ambiguities: (1) The alloy composition under test was $51 \% \mathrm{Cu}-49 \% \mathrm{Zn}$. This composition lies outside the regime where shape memory behaviour can be expected [3]. (2) It is well known that microstructure of electrodeposited alloys are different from those obtained metallurgically. However, since the micro-structure of the alloy was not determined no comparison of shape memory effect 
between these two methods can be made. (3) There was no direct evidence to prove that the alloy switched between martensitic and austenitic phases. Therefore, it remains unclear if electrodeposited and metallurgically prepared alloys undergo exactly the same kind of phase transformation as that observed in those prepared by metallurgical means.

The aim of this investigation is to electroplate shape memory thin films and carry out systematic studies regarding their shape memory behaviour. In order to do so, one has to establish the engineering, electrochemical, and hydrodynamic parameters necessary for the production of a $\mathrm{Cu}-\mathrm{Zn}$ shape memory alloy. The first parameter is the choice of the electrolyte from which both metals, copper and zinc, can be plated. Secondly, the polarisation data for single metals and the alloy have to be determined. Thirdly, the effect of mass transfer and temperature on alloy composition has to be established. These three separate variables combine to yeild the overall alloy composition and microstructure, which determines the shape memory behaviour of the electroplated thin film.

\section{THE COPPER-ZINC ELECTRODEPOSITION SYSTEM}

In order to electroplate a copper-zinc alloy (brass), at first a suitable electrolyte has to be chosen. Commercially, brass is electrodeposited from a cyanide bath, since it yeilds coherent deposits with desirable properties. However, cyanide baths are very toxic and unstable, and exhibit low current efficiency and sluggish mass transport. In this work, a pyrophosphate based electrolyte was chosen for electrolysis which is frequently used in the industry to plate copper on printed circuit boards. The pyrophosphate electrolyte is chemically stable, it has good throwing power and current efficiency; moreover, it is non-corrosive and non-toxic.

The co-deposition of copper with zinc from a pyrophosphate bath has been investigated by de Kay Thompson [4] and Stabrovsky [5] and more recently Rama Char and associates [6]. Prior studies have shown that $\mathrm{Cu}-\mathrm{Zn}$ alloys containing $40-99 \%$ of copper [7] can be obtained from pyrophosphate electrolytes. Deposits have been found to be coherent, smooth and fine grained. The pyrophosphate bath operates between $\mathrm{pH}$ 8-9: in this range the solution is highly buffered and there is no chemical breakdown of the constituents such as the hydrolysis of pyrophosphate to orthophosphate or formation of precipitates. The solution must contain an excess of complexant, namely potassium pyrophosphate for successful complexation of the metallic ions and to increase electrical conductivity. It is critical to maintain the ratio of pyrophosphate to metal ion concentration above $7: 1$, because if the ratio falls below this level the bath becomes unstable [7]. Nitrate ions are also added to the electrolyte because it acts as a proton acceptor. The chemical composition of the pyrophosphate electrolyte used in this study is shown in Table 1.

TABLE 1

Composition of Electrolyte used in Plating Experiments

$\begin{array}{ll}\mathrm{Cu}_{2} \mathrm{P}_{2} \mathrm{O}_{7} \cdot \mathrm{H}_{2} \mathrm{O} & 0.01 \mathrm{M} \\ \mathrm{Zn}_{2} \mathrm{P}_{2} \mathrm{O}_{7} & 0.09 \mathrm{M} \\ \mathrm{K}_{4} \mathrm{P}_{2} \mathrm{O}_{7} & 0.23 \mathrm{M} \\ \mathrm{KNO}_{3} & 0.12 \mathrm{M}\end{array}$

pH adjusted with pyro-phosphoric acid $\quad 8.4$ 
The second engineering parameter that has to be ascertained is the current or potential that has to be applied to obtain a certain alloy composition. When a metal ion, $\mathrm{M}^{\mathrm{n}+}$, is reduced at a cathode, a complex series of events occur: (1) the metal ion has to be transported to the cathode surface by diffusion, migration, and convection, (2) the ion is adsorbed at the surface of the electrode and transformed to its metallic form by an electron discharge reaction, and (3) then it is incorporated into growing deposit which may involve solid state diffusion processes. Either one or many of these processes can limit the rate of metal deposition during electroplating. Polarisation data for metal deposition provides information on the rate limiting step for each of the reactions occurring at the cathode, which is used to predict alloy composition.

Cathodic polarisation data at a rotating disk electrode for electrolytes containing either copper or zinc are shown in Figure 2. The data are typical of regular electrodeposition systems which are limited by electrochemical kinetics. Copper, which is the more noble metal is reduced first, at a reversible potential of $-0.208 \mathrm{~V}$ and zinc, which is the less noble component is reduced only beyond a electrode potential of $-1.157 \mathrm{~V}$. The polarisation data of neither metal show a mass transfer limiting current, which shows that mass transfer to the cathode does not limit the rate of metal reduction. During the codeposition of these metals the current efficiencies varied between $20-55 \%$ for copper and $5-10 \%$ for zinc. Whereas the copper current efficiency diminished with increasing cathodic overpotential, current efficiency for zinc reduction increased.

\section{Cathodic Polarisation}

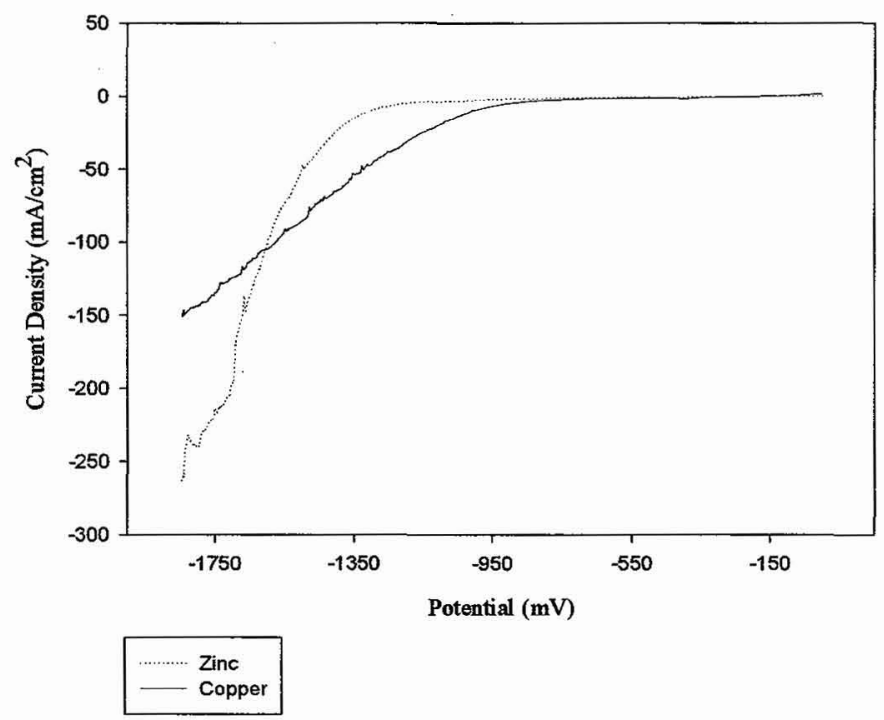

Figure 1: Polarisation curves for electrolytes containing either $0.01 \mathrm{M} \mathrm{Cu}_{2} \mathrm{P}_{2} \mathrm{O}_{7} \cdot \mathrm{H}_{2} \mathrm{O}$ or $0.09 \mathrm{M} \mathrm{Zn}_{2} \mathrm{P}_{2} \mathrm{O}_{7}$ and potassium pyrophosphate and nitrate concentrations shown in Table 1. 
In order to deposit brass, the electrode should be set at a potential where both copper and zinc are reduced. Figure 1 clearly shows that both copper and zinc are co-discharged when the cathode potential is set below $-1.157 \mathrm{~V}$. At these potentials the alloy compositions are computed from the partial currents of copper and zinc according to the following equation

$$
\chi_{C u}=\frac{i_{C u}}{i_{C u}+i_{Z n}}
$$

where $\chi_{\mathrm{Cu}}$ is the copper content in the alloy. The partial currents for copper and zinc are computed by multiplying the current shown in Figure 1 with the current efficiency at any particular potential. In order to determine the current efficiency, the coulombic charge consumed during electrodeposition was compared with the total amount of metal discharged, which was computed from gravimetric measurements.

The agreement between Equation 1 and compositions of electroplated alloys were found to be satisfactory only at low cathodic overpotentials. For applied cathodic overpotentials of up to $-1.5 \mathrm{~V}$, the alloy compositions were found to be within $\pm 3 \%$ of predicted values. At higher cathodic overpotentials, the alloy composition was found to differ by $5-15 \%$ from the value calculated using Equation 1. For example, at $-1.85 \mathrm{~V}$, the current densities for copper and zinc are $153 \mathrm{~mA} / \mathrm{cm}^{2}$ and $269 \mathrm{~mA} / \mathrm{cm}^{2}$, respectively, with current effiencies of $9.7 \%$ and $7.3 \%$ respectively. According to Equation 1, electrodeposition at this potential should produce a $43.05 \% \mathrm{Cu}$ brass. The alloy composition, however, was found to be $54 \% \mathrm{Cu}$. This error is attributed to fluctuations in current density during plating as well as difficulty in assessing ohmic drop within the electrolyte.

\section{DEPOSIT CHARACTERISTICS}

A scanning electron micrograph of an electrodeposited $\mathrm{Cu}-\mathrm{Zn}$ foil is shown in Figure 2. The foil was plated onto a rotating steel cylinder, and then peeled off for electron micrography. Three separate metallic layers are visible in the figure: (1) the bottom layer is pure copper which was plated on to the steel substrate because brass did not adhere to steel, (2) the second layer, about $1.5 \mu \mathrm{m}$ thick, is a $\mathrm{Zn}$ rich $\mathrm{Cu}-\mathrm{Zn}$ alloy, and (3) the top layer is $54 \% \mathrm{Cu}$ brass. EDX measurements showed that the Zn-rich layer contained about $80 \% \mathrm{Zn}$ which indicates the formation of $\mathrm{CuZn}_{5}$, an intermetallic. This layer was observed in all electroplated samples, and strongly suggests that electrodeposition of brass on a copper substrate is preceded by the formation of this intermetallic.

The $\mathrm{x}$-ray diffraction pattern for the $54 \%$-copper $\mathrm{Cu}-\mathrm{Zn}$ foil is presented in Figure 3 . The phases corresponding to the different peaks is shown in Table 2 . This analysis reveals the presence of pure copper, corresponding to the bottom layer shown in the SEM, the intermetallic $\mathrm{CuZn}_{5}$, and both $\alpha$ and $\beta$ phases, where a martensitic transformation is expected to be observed. The equilibrium diagram for $\mathrm{Cu}-\mathrm{Zn}$ shows that a $54 \% \mathrm{Cu}$ should contain predominantly $\alpha$ and $\beta$ phases, in agreement with the phases observed in the electrodeposit. 


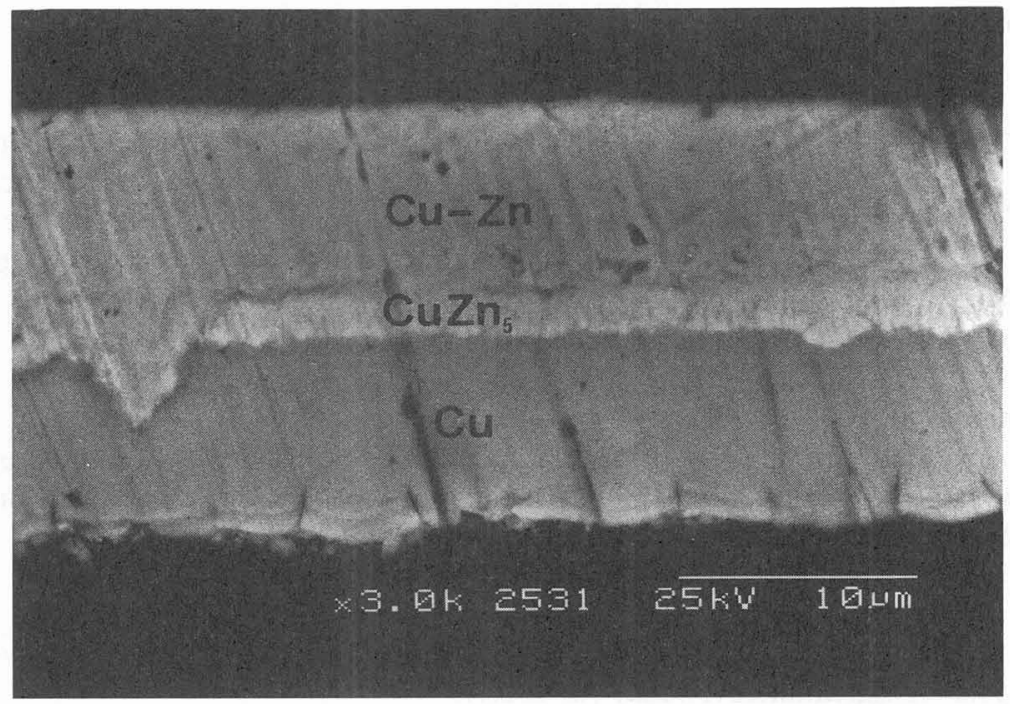

Figure 2: Scanning electron micrograph of $54 \% \mathrm{Cu}$ brass deposited from a pyrophosphate bath. Electrode potential $-1.85 \mathrm{~V}$

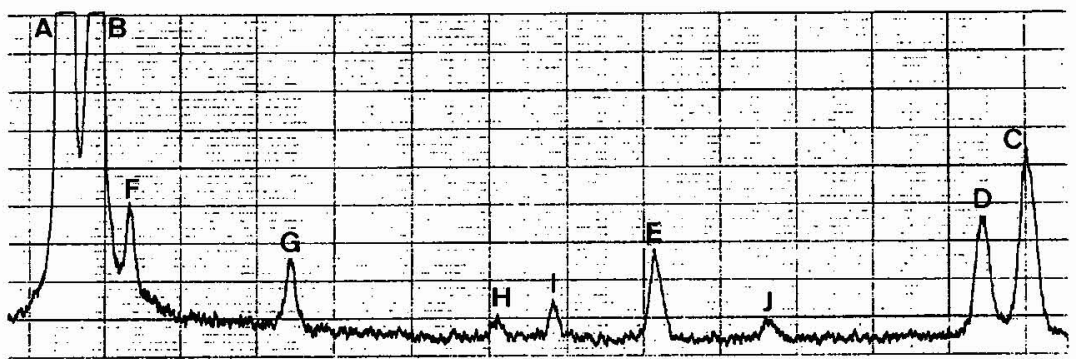

Figure 3: X-ray diffractogram for an electrodeposited 54\%Cu brass. An explanation of the marked peaks are presented in Table 2.

TABLE 2

\begin{tabular}{|c|c|c|c|}
\hline PEAK MARKS & $2 \theta$ Values & Peak Strength & Phase Response \\
\hline $\mathrm{A}$ & 41.75 & Strong & $\beta, \mathrm{CuZn_{5 }}$ \\
\hline B & 42.80 & Strong & $\alpha, \beta, \mathrm{Cu}$ \\
\hline $\mathrm{C}$ & 91.25 & Good & $\alpha$ \\
\hline D & 89.63 & Average & $\mathbf{C u}$ \\
\hline $\mathrm{E}$ & 77.50 & Average & $\beta, \mathrm{CuZn_{5 }}$ \\
\hline $\mathrm{F}$ & 44.00 & Average & $\alpha, \mathrm{CuZn}_{5}$ \\
\hline $\mathbf{G}$ & 50.12 & Average & $\alpha$ \\
\hline $\mathrm{H}$ & 57.12 & Weak & $\mathrm{CuZn}, \mathrm{Cu}$ \\
\hline$I$ & 73.75 & Weak & $\beta, \mathrm{Cu}$ \\
\hline $\mathbf{J}$ & 81.75 & Weak & $\mathrm{CuZn_{5 }}$ \\
\hline
\end{tabular}




\section{CONCLUSION}

$\mathrm{Cu}-\mathrm{Zn}$ alloys have been electrodeposited from a pyrophosphate electrolyte containing $\mathrm{Cu}_{2} \mathrm{P}_{2} \mathrm{O}_{7}$, $\mathrm{Zn}_{2} \mathrm{P}_{2} \mathrm{O}_{7}$ salts containing an excess of $\mathrm{K}_{4} \mathrm{P}_{2} \mathrm{O}_{7}$ and $\mathrm{KNO}_{3}$. Current-potential data for both copper and zinc, as well their plating current efficiencies was determined from electrochemical polarisation experiments. Copper deposition commenced at potentials below $-0.208 \mathrm{~V}$ whereas zinc was deposited only below $-1.157 \mathrm{~V}$. The current efficiencies for both metals was found to be low; typically $20-50 \%$ for copper and $5-10 \%$ for zinc. Alloys of brass containing $30-50 \% \mathrm{Cu}$ were produced by electrodeposition. The deposits were found to consist predominantly of $\alpha$ and $\beta$ phases.

\section{Acknowledgement}

This work was supported by a university research studentship, University of Newcastle-upon-Tyne, and the CIBA Fellowship Foundation ACE award. The authors would like to thank Dr. Gotthardt and Dr. Bidaux of The Swiss Federal Institute of Technology for helpful discussions.

\section{References}

[1] Johnson A.D. and Busch J.D., Proc. of the 1st International Conference on Shape Memory and Superelastic Technologies, Monterey, 1994.

[2] Frimpong J., Sonu C.H., Hymer T.R. and O'Keefe T.J., Proc. of SPIE, Washington, USA, 1993, pp362-372.

[3] Hansen, M, Anderko, K, "Constitution of Binary Alloys, Metallurgy and Metallurgical Engineering Series (Mc-Graw-Hill Book company, NY, 1958) pp. 649-655.

[4] Thompson M. de Kay, Met. and Chem. Eng. 10, (1912) 458-461.

[5] Stabrovsky, A. I. Zhur. Fiz. Khim., 26, 949-955 (1952).

[6] Sree V. and T.L. Rama Char, J. Sci. Ind. Research (India), 16A, (1957) 325-326.

[7] Lowenheim F.A., "Modern Electroplating”, (Technical Reference Publications Ltd.; Arrowsmith, Bristol, UK, !955). 